\title{
Self-rated health: Importance of use in elderly adults
}

\author{
José MaURICIO OCAMPo, MD*
}

\section{SUMMARY}

Introduction: The concept of self-rated health (SRH) was conceived during the first half of the twentieth century. Since then, numerous studies have documented the validity of its measurement and it has been widely accepted as a reliable measurement of overall health. SRH is considered a subjective measurement integrating the biological, mental, social, and functional aspects of an individual.

Objective: To review the literature to determine theoretical determinants, related outcomes, and utility of SRH in elderly adults (EAs).

Methods: The databases reviewed were Medline, SciELO, EMBASE, Science Direct, Proquest, and Ovid, along with information available in websites from international health agencies.

Results: SRH is considered a sensitive measurement of overall health in EAs. It is influenced by physical function, the presence of disease, the existence of disabilities, functional limitations, and by the rate of aging. Many studies suggest it may be modified by demographics, as well as by social and mental factors. Thus, the perception of health is the result of multiple and complex interactions of variables determining it at any given time. SRH is based on systems theory and the bio-psychosocial health model. It has proven to be a significant independent predictor for development of morbidity, mortality, and disability in basic physical and instrumental daily life activities among elderly adults.

Conclusion: In addition to reflecting the overall health status of EAs, SRH can provide information to aid health personnel and decision makers in the development and implementation of health promotion and disease prevention programs, as well as the adequacy and planning of different levels of care for this population.

Keywords: Self-rated health; Elderly adults; Daily life activities; Aging; Bio-psychosocial model.

\section{Auto-percepción de salud: importancia de su uso en adultos mayores}

\section{RESUMEN}

Introducción: El concepto de auto-percepción de salud (APES) fue introducido a mitad del siglo XX. Desde entonces, numerosos estudios han documentado la validez de su medición y ha sido ampliamente aceptado como una medida confiable del estado de salud general. La APES se considera una medición subjetiva que integra factores biológicos, mentales, sociales y funcionales del individuo.

Objetivo: Realizar una revisión de la literatura para determinar fundamentos teóricos, factores determinantes, desenlaces relacionados y utilidad de la APES en adultos mayores (AM).

Metodología: Se utilizaron las bases de datos Medline, SciELO, EMBASE, Science Direct, Proquest, Ovid, así como la información disponible en sitios web de organismos sanitarios internacionales.

Resultados: La APES se considera una medida sensible del estado general de salud en los AM. Está influida por la función física, la presencia de enfermedades, la existencia de discapacidades, de limitaciones funcionales y por el tipo de envejecimiento. Muchas investigaciones sugieren que la pueden modificar variables demográficas, sociales y mentales. De esta manera, la APES es la resultante de múltiples y complejas interacciones de variables que la determinan en un momento dado. La APES se fundamenta en la teoría de sistemas y en el modelo bio-psicosocial de salud. Se ha demostrado que se comporta como un predictor independiente y significativo para desarrollar morbilidad, mortalidad y discapacidad, tanto en las actividades básicas cotidianas como en los aspectos físico e instrumental en adultos mayores.

Conclusión: La APES además de reflejar el estado de salud global del AM, puede brindar información que ayude al personal de salud y a tomadores de decisiones en el desarrollo e implementación de programas de promoción de la salud y prevención

* Assistant Professor, Department of Family Medicine, Universidad del Valle, Cali, Colombia. e-mail:jmocampo2000@yahoo.com.ar

Received for publication February 19, 2010 Accepted for publication May 15, 2010 
de la enfermedad, así como en la adecuación y planificación de diferentes niveles asistenciales para este grupo poblacional.

Palabras clave: Autopercepción de salud; Adulto mayor; Actividades básicas cotidianas; Envejecimiento; Modelo bio-psicosocial.

Population aging is probably the most important demographic phenomenon in the world during the end of the $20^{\text {th }}$ century and beginning of the $21^{\text {st }}$ century ${ }^{1}$. The population of elderly adults (EA), defined as individuals 60 years of age and older present $2.4 \%$ growth rates, compared to $1.7 \%$ for the total population. It is expected that this growth rate increases by $3.1 \%$ as of 2010 . In absolute numbers, this shows that the EA group will increase from 616-million in 2000 to 1.209-billion in 2025 , implying that this population group will double in numbers every 25 years ${ }^{1}$.

The aging process can lead to gradual deterioration of mental and physical health conditions, reduction in expected years of active and healthy life, and complete or partial cease in participation in the labor market ${ }^{2}$. Likewise, alterations in the health status -characteristic of advanced age- are more chronic than acute and more progressive than regressive. This makes it necessary to know the state of health of this population so it can be intervened from the vantage point of health promotion and disease prevention, as well as for the adequacy and planning of the care offered and for the development of health programs.

To accomplish this, it is necessary to start by being clear on the concept of health status as defined by the World Health Organization (WHO) in 1945, thus: " $A$ complete state of physical, mental, and social wellbeing and not merely the lack of disease or disability ${ }^{3}$. This definition, in schematic manner, circumscribes health within a quadrant in which the extremes correspond to the physical, mental, social, and spiritual dimensions. Additionally, it is stressed that the concept of health should bear in mind the human being as a total and integral being. This focus permits visualizing the four dimensions mentioned in independent and integrated manner in individuals, in whom these dimensions function as a complete entity and in relation to the world around them.

Consequently, this holistic view makes the assessment of the state of health to become a complex activity, particularly in EAs because during the aging process a series of internal and external modifications take place, as well as changes in the functions of the individual's organs and systems. This becomes evident when the person is exposed to stressful situations that induce changes in the state of health, as a product of lower functional reserve and lower capacity for response and adaptation, a phenomenon known as homeoestenosis, which can lead to greater probability of organic failure and illness ${ }^{4}$.

With respect to assessment of state of health in EAs, it is fundamental to bear in mind that it is integral and such then go beyond the traditional clinical history. Therefore, this assessment must consider the psychological, familial, social, economic, and functional dimensions ${ }^{5}$. It is worth mentioning that this assessment, more than in other age groups, implies subjectivity, because it depends on the interaction among physiological conditions, functional abilities, psychological wellbeing, and social support. For this reason, the evaluation of the state of health should not bear in mind only the strictly medical aspects, it should go beyond, being relevant for clinicians, decision makers, and researchers working with this population group ${ }^{5}$.

\section{WHAT IS SELF-RATED HEALTH STATUS AND WHAT ARE ITS ORIGINS?}

In spite of the generalized use of the term selfperception, there is no clear definition of its meaning in scientific literature; there is also no clarity of its theoretical concept. Self-perception can be defined as the concept individuals have of themselves and based on such; they process and organize the information of their context within a structure that provides the basis of principles to act in the present and in the future. Thus, individuals maintain and develop a basic scheme of their own selfperception throughout their whole lives ${ }^{6}$.

Self-Rated Health has been employed in a broad variety of scenarios with different population groups and for a great number of objectives ranging from screening for specific health conditions to studies designed to aid in decision making for individuals in crisis situation, like depressive states or the capacity to decide on changing domicile ${ }^{7}$. As mentioned, in the previous paragraph the term SRH has been used to refer to the response made by individuals when asked about their 


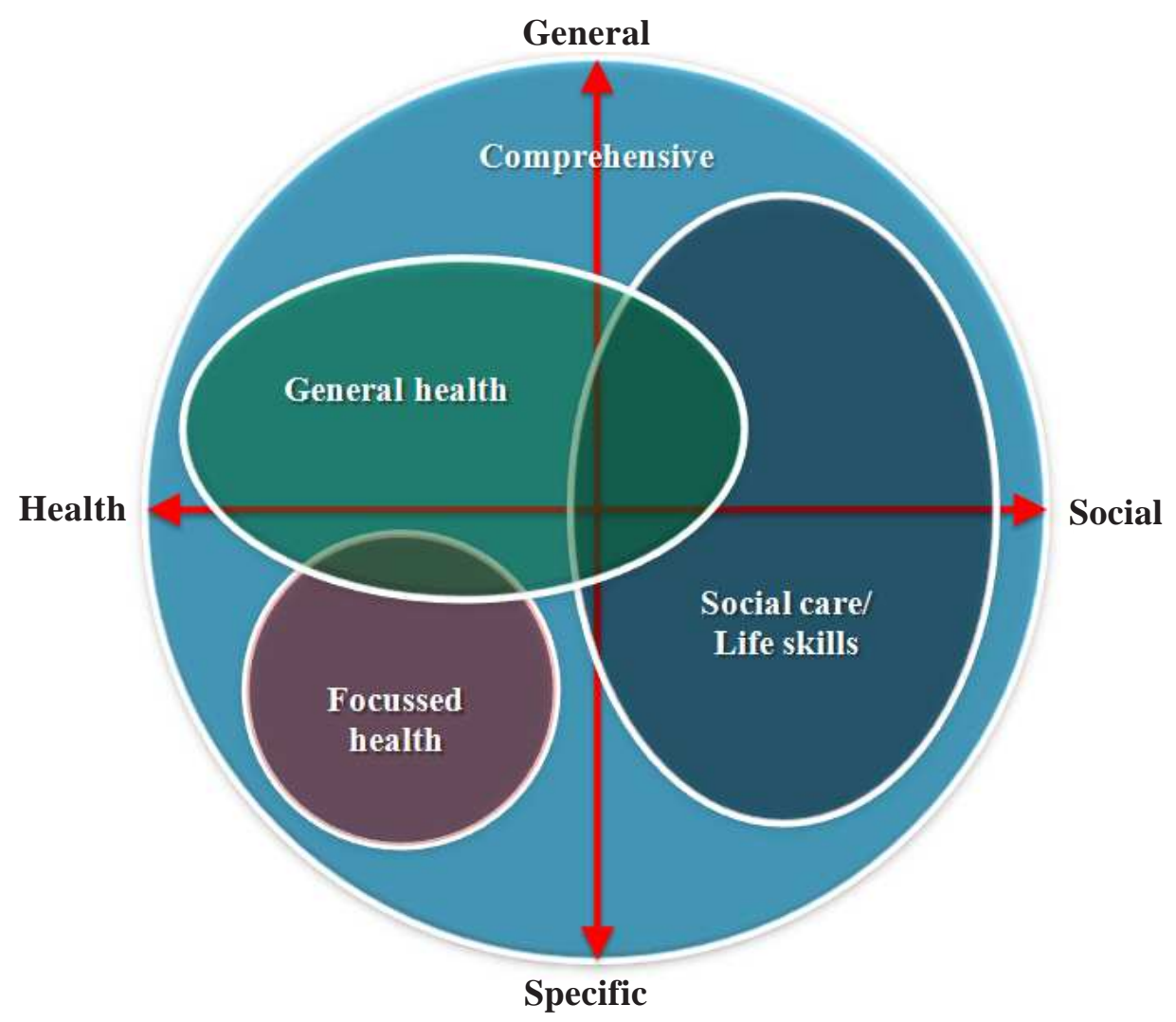

Graphic 1. Types of self-perception with the different dimensions and interactions

Taken and adapted from: Griffiths P, Ullman R, Harris R. Self-assessment of health and social care needs by older people: a multi-method systematic review of practices, accuracy, effectiveness and experience. London: NCCSDO, 2005. [Date accessed: 18 December 2006]. Available in: http://www.sdo.lshtm.ac.uk/sdo302002.html

state of health; hence, it can be applied to all self-reports of state of health or of specific symptoms like pain or the sensation of dyspnea, fatigue, or tiredness ${ }^{7}$.

In other words, SRH is a way of evaluating the state of health in people, which integrates information on the biological, mental, functional, and spiritual dimensions of an individual's health ${ }^{8}$. Thereby, it is considered that SRH represents the perception individuals have of the different dimensions of their state of health; accordingly, SRH can be classified as a result and integral variable, which permits inferring that it can encompass the different dimensions of the human being ${ }^{9}$.

The SRH concept has been included in different research projects since the 1950s and ever since then diverse studies have shown its usefulness in documenting the state of health self-reported by EAs during a given moment and also in predicting future health-related events $^{8,9}$. This shows the great interest in using SRH when conducting research that assesses state of health; in fact, it is already part of health surveys carried out with EAs.

\section{WHAT ARE THE THEORETICAL FOUNDATIONS OF SRH?}

For the theoretical understanding of SRH, a model made up of four dimensions is proposed. Said dimensions are defined by their content, i.e., by the aspect each seeks to evaluate. In turn, between dimension and dimension there are multiple interactions. The type of self-perception we wish to assess depends on the dimension predominating in such interaction and on its characteristics, for example, if the approach tends to be more general or specific and if it seeks to evaluate social aspects, health aspects, or both ${ }^{7}$ (Graphic 1).

Hereinafter, we present the different approaches of the evaluation according to the dimensions and type of self-perception, based on the proposal by Griffiths et al. ${ }^{7}$ 
- Health care approach. This domain focuses on assessing specific health aspects and problems. Selfperception can collaborate and, on occasion substitute the assessment made by the health professional. For example, based on this domain, research has been conducted to identify elderly adults with mental disorder, hearing and vision loss, and problems with nutrition, mobility, and function. This type of self-evaluation can help to predict current needs and some future ones. When an approach to self-perception is conducted through this domain, the individual's internal factors are exclusively considered.

- General health care approach. This domain is used for evaluating a broad range of factors related to health care. The objective here is to improve general health care and mediate in the patient's relationship with healthcare professionals. Mental health status, functional capacity, social contacts, and use of health services are among the aspects investigated in this domain. This type of assessment permits determining the individual's current needs, and can sometimes aid in predicting future needs, although it does not permit identifying the resources available for the individual. When approaching self-perception through this domain, internal and external factors of the individual are considered.

- Social care and abilities for life approach. This domain focuses on assessing everyday situations and aspects the health professional does not frequently evaluate during consultation, like the individual's capacity to drive a vehicle and the possibility of being involved in accidents. Aspects related to home safety along with risks of falling are also assessed. This provides greater elements for patient assessment and care. When approaching self-perception through this domain, internal factors of the individual are considered, as well as external factors like environment, employment, and leisure time.

- Multidimensional approach. This domain involves external factors like social aspects and internal factors like the individual's state of health and wellbeing. The main objective of this domain lies in identifying necessities and offering information that permits the individual to adequately satisfy such. Because of the great number of factors this domain can encompass, it is possible that it includes elements of self-assessment of social care along with life skills and the impact of the state of health. The distinction between the domain of general health care and the multidimensional approach lies on the balance and weight given to health problems and services. If the approach is multidimensional, a global approximation is made of the aspects related to the individual's state of health, unlike general health care that emphasizes health needs and services for the individual.

Different research has shown that measuring personal health perception is a useful global indicator of the population's level of health, given that it reflects social and biological elements ${ }^{10,11}$. In effect, SRH is one of the mostly used types of self-perception to determine the state of health in EAs from a subjective perspective, because it shows multiple aspects of the individual's state of health that could turn out to be difficult to obtain via traditional quantitative research methods. For example, objective measurements often evaluate only one aspect, as with levels of glycated hemoglobin that are used in determining the state of control of diabetes mellitus. It could be said that the subjective and objective measurements are complementary and necessary when learning of the individual's state of health. Consequently, SRH is considered a type of self-perception employing elements from the multidimensional approach according to $\mathrm{WHO}$ recommendations ${ }^{12}$.

For the theoretical explanation of SRH, we used the bio-psychosocial model suggested by Engel ${ }^{13}$, which approaches health from a holistic view and which considers the individual a being participating in the social, psychological, and biological spheres; in contrast to the analytical, reductionist, and specialized biomedical model, which additionally takes into account the person as an object and ignores that person's subjective experience as a possibility of also being studied in scientific manner ${ }^{14}$.

On the contrary, the bio-psychosocial model considers an illness not as the lack of health or simply physical health but also any psychological or social interaction that can affect and individual's state of illness/disability.

Understanding the bio-psychosocial model requires an approach to the General Systems Theory, whose main exponent was Ludwig von Bertalanffy ${ }^{15}$, and stemming from this approach there can be integration between the parts and the whole, where relationships are not unidirectional but bidirectional and there is no cause and effect unicausal relationship, but one of multifactorial effect. With this, an important change is produced given that understanding the phenomena the 


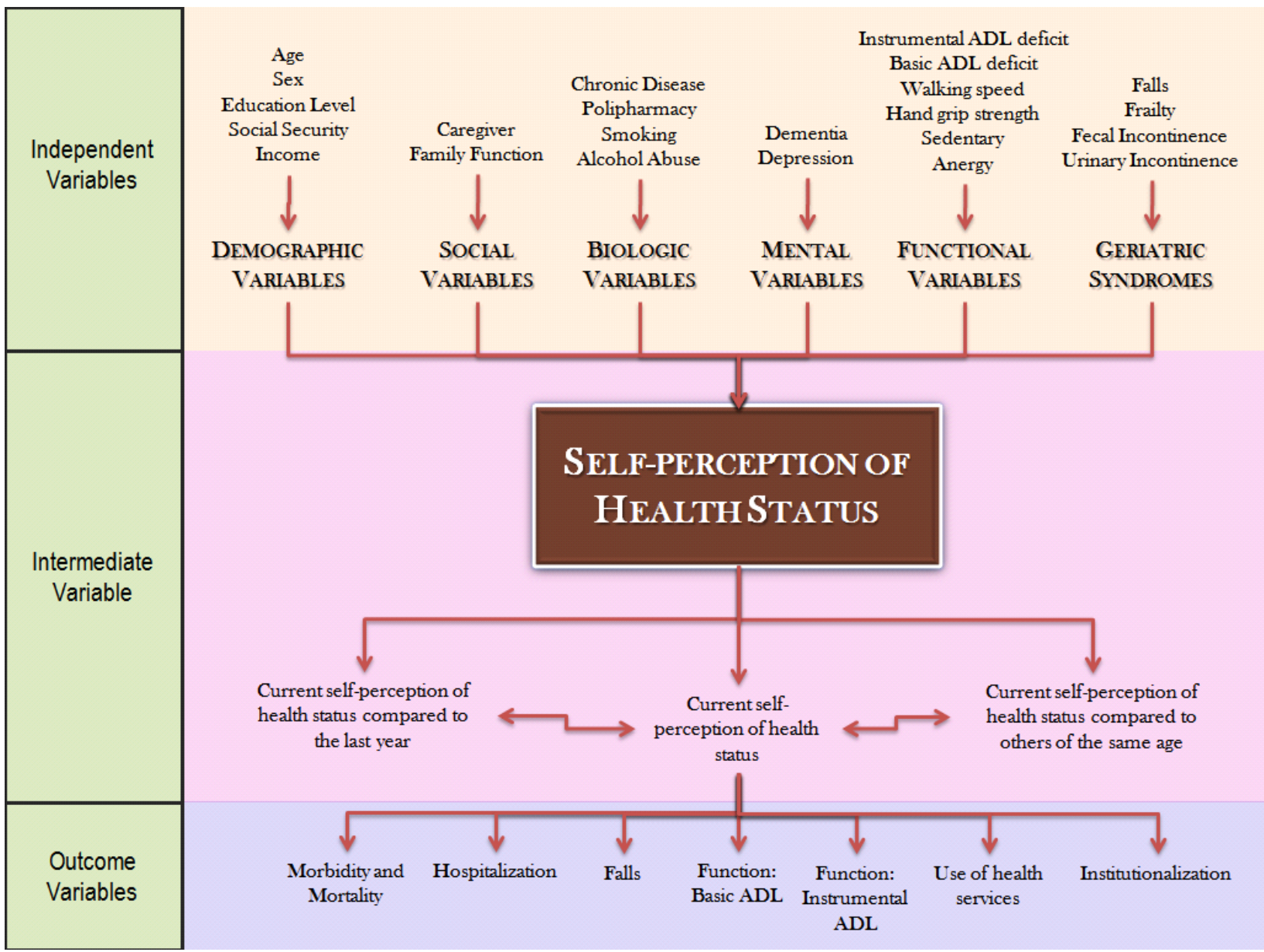

\section{Graphic 2. Theoretical Model of Self-rated Health}

simple thought «first $A$ then $B$ » is not sufficient, but rather the capacity of thinking of the complexity of the multiple interactions.

With respect to the SRH model suggested, a set of independent variables is shown that are grouped according to the state-of-health dimension to which they belong in social, demographic, biological, mental, and functional terms. From a subjective perspective, individuals will self-report their state of health. This implies that people must undergo complex reasoning involving multiple interactions of independent variables for the self-report of the state of health.

This interaction of multiple variables permits obtaining information on the state of health of the elderly adult during different moments, i.e., the current state of health compared to that of other individuals of similar age and the current state of health actual compared to that of the previous year. Additionally, said interaction may offer prospective elements that help to anticipate the development of any given event in the future.

On this matter, SRH behaves as an intermediate variable among the independent variables that determine it and the different outcomes to which it has been associated like death, hospitalization, and functional impairment among others ${ }^{16}$ (Graphic 2).

\section{WHY IS THERE INTEREST IN RESEARCHING SRH?}

Many health professionals treating elderly adults focus mainly on factors related to physiological measurements (laboratory values), mental state (presence of depression), life styles (smoking habit), or functional state (Basic Daily Activities). However, studies have shown that the perceptions offered by EA son their state of health and wellbeing can be as 
important as the clinical variables to evaluate and predict the evolution of the state of health over time ${ }^{9}$.

Unfortunately, current clinical medicine practice has progressively stopped listening to patients (their ailments), and has replaced this for observation or measurements like diagnostic images or application of scales ${ }^{17}$. This has caused medicine to go from being a discipline involved with listening and feeling, to a discipline of seeing and doing; proof of this is the increase in the algorithms and guides for clinical practice in recent years. That could explain why the question on the perception of the state of health is often ignored; in fact, the medical practice prefers to inquire more about quantitative than qualitative aspects, for example, on inquiring about sleep the question is how many hours does the patient sleep per day, rather than how does the patient feel with his/her sleeping habits ${ }^{18}$.

As has been insisted upon in this article, different studies have shown that assessing the personal perception of the state of health is useful because it allows globally describing the population's level of health given that it reflects elements that are not merely biological, but also psychological, social, and functional ${ }^{10,11}$. It has also been employed to compare the state of health of EAs from different countries, because it can be easily obtained and reflects multiple aspects of the state of health that could be difficult to gather by other methods ${ }^{19}$.

Analyzing the factors related with SRH will permit identifying health needs and evaluating programs and interventions aimed at EA population group. Hence, it should be included in research for the following reasons ${ }^{9}$ :

- It is a global measurement of the state of health, psychological wellbeing, and quality of life related to health, offering much more information than other variables used in traditional research, for example, the presence of chronic illness or total cholesterol values, among others.

- It is easily obtained through one single question: «Do you consider your general health status: excellent, very good, good, regular, or poor?» This shows that specialized personnel are not required to assess a population's general state of health.

- It is an indicator significantly associated with the population's state of health and with mortality; consequently, it can be used approximately to determine healthcare needs.

- It behaves as a screening test because it helps to identify high-risk individuals in prodromal stages for the development of adverse health events like falls, and hospitalization among others.

- At the individual level, it may predict mortality in the elderly; thereby, useful in current or future behavioral models to determine, for example, the use of retirement services or plans.

- It may be used to tailor health services and establish priorities in healthcare.

\section{WHAT STUDIES HAVE BEEN CONDUCTED IN LATIN AMERICA ON SRH IN ELDERLY ADULTS?}

In Colombia, not much research has been done on SRH in EA populations. One of these was done by Gómez et al. ${ }^{20}$ who carried out an observational analytical, cross-section study in the city of Manizales, where SRH assessment was done and established a correlation with the presence of co-morbidity and functional state. The researchers found an important association among SRH, chronic disabling disease, and functional capacity, measured via the Barthel scale, which evaluates Basic Daily Activities in the physical aspect.

Recently, Parra et al. ${ }^{21}$ conducted a multilevel observational analytical, cross-section study to determine the association between urban and environmental characteristics in the city of Bogota with SRH and quality of life related to health. A positive association was found between perception of neighborhood safety with good SRH and quality of life related to health. Likewise, the availability of recreational spaces like safe parks that promote social interaction and recreational activities was associated to good SRH and quality of life in the mental health domain. On the contrary, zones with high levels of noise were associated to bad SRH and quality of life. The value of this research lies in that it is the first study conducted in a highly urbanized city in a country with low to medium economic income. Additionally, it offers inputs to implement interventions aimed at improving the quality of life and SRH of EAs living in cities with environmental and socioeconomic characteristics that are similar in several Latin American nations.

Hambleton et al. ${ }^{22}$ carried out an observational analytical, cross-section study, employing information 
belonging to the population of Barbados in the $« \mathrm{SABE}$ project», which is a multicenter survey conducted in seven urban centers in Latin America and the Caribbean to evaluate the factors impacting the health and wellbeing of EAs 60 years of age or more. The study sought to determine the relative contribution of past events and current experiences to the state of health of EAs for the purpose of conducting opportune sanitary interventions for said population. It was found that past experiences of socioeconomic aspects influenced SRH, and over half of the influence exerted by past events was measured by current experiences related to the socioeconomic situation, life style, and the presence of illnesses. Therefore, when caring for the elderly, consideration must be made for intervention of the risk factors related to life style. The importance of this research lies on the relationship established by the authors between social and clinical determinants with SRH. Consequently, when implementing programs to reduce poverty and increase Access to healthcare and education, long-term strategies should be considered aimed at improving the health of the elderly of the future.

Alves et al. ${ }^{23}$ employed information from a population in Sao Paulo, Brazil from the «SABE project» to carry out an observational analytical cross-section study. The purpose of that work was to determine, via SRH, the relationship between demographic, social, and economic factors along with the presence of chronic disease and functional capacity in EAs 60 years of age and older. The study also sought to evaluate if there were gender differences. It was found that presence of chronic disease in relation to gender was the greatest association to determine SRH, i.e., males presenting four or more chronic illnesses had 10.53 times greater opportunity for bad SRH; similarly, for females it was 8.31 times. Likewise for educational level, income, and functional capacity were related to SRH. The novel aspect of this research is the approach of SRH from the multidimensional perspective, and that it may be useful for decision makers when implementing actions from the health sector seeking to promote wellbeing and quality of life for the elderly.

Reyes et al. ${ }^{24}$ led an observational analytical crosssection study, employing information from the multicenter survey in the «SABE project». The aim was to determine the relationship between religiosity and SRH. It was found that most (90\%) reported having some religious affiliation, and within this group $80 \%$ considered religion important in their lives. The EAs who considered religion very important in their lives had lesser opportunity of reporting bad SRH when compared to those who considered religion less important. This is one of the first studies carried out in urban centers in Latin America and the Caribbean showing the importance of religiosity in the state of health of elderly adults.

\section{HOW IS SRH MEASURED?}

In recent years, surveys employed to assess state of health have used diverse questions trying to integrate the different dimensions of the human being ${ }^{25}$. These types of surveys take into account the self-report of health, through a subjective, global, and integrating evaluation of the state of health done by the individual. This includes the perception of small physiological-type variations, negative or positive attitudes on life and disposition for healthy conducts; these are related to clinical morbidity, which is influenced by social, cultural and emotional aspects ${ }^{7}$.

To assess SRH, a variety of schemes of structured questions has been designed with their possible responses, among which there is the WHO version employed in Europe and the United States version.

The World Health Organization version, which is recommended and used in Europe, takes a range of responses from very good to very poor. It is characterized because it groups the responses into several categories, of which two are positive (very good and good); one neutral (regular); and two negative (poor and very poor $)^{12}$.

The better known United States version is employed by Bjorner et al. ${ }^{26}$ who initially used the question: How do you rate your state of health?; with four possible response options: excellent, good, regular, or poor. Then, a fifth «very good» response option was added, along with an additional question on the current general state of health compared to that of the previous year: How would you rate your current general state of health, compared to that of the previous year? which is how it is known and applied currently in different research projects. These last additions were included because of the study conducted by Ware et al. ${ }^{27}$ who used the abbreviated SF-36 form.

Regarding SF-36, this is the instrument developed for 
Table 1

Questions used to assess the state of health via SRH

1. Comparison of the current state of health with that of a year before:

How would you rate your current general state of health, compared to your state of health a year ago?

Much better now Somewhat better More or less the same Somewhat worse now Much worse now

than a year ago now than a year ago now as a year ago than a year ago than a year ago

2. Perception of the current state of health:

In general, would you say your health is (USA version):

Excellent Gery good Good Regular Poor

In general, would you say your health is (European version):

$\begin{array}{llll}\text { Very good } & \text { Good } & \text { Regular } & \text { Poor }\end{array}$

3. Comparison of the current state of health with other individuals of similar age

Comparing your health to that of other people the same age, yours is:

Better More or less equal

Worse

Don't know

use in the Medical Outcomes Study, from an extensive battery of questionnaires, whose final format provides a profile of the state of health ${ }^{28}$. It includes 36 points grouped into 8 scales: physical functioning, physical performance, body pain, emotional performance, mental health, vitality, general health, and social functioning, plus an additional one: change of health over time. These points assess positive and negative states of mental and physical health. For each dimension, the points are coded, aggregated, and transformed into an ordinal scale ranging from 0 (the worst state of health for that dimension) to 100 (the best state of health), without generating a global index.

This instrument has been used in over 40 countries in the International Quality of Life Assessment Project. It is documented in more than 1,000 publications; its usefulness in estimating disease burden is described in over 130 conditions and it is used worldwide because of its briefness and comprehension. It is worth pointing out that in the assessment made on Colombian adults a Spanish version was obtained showing complete coincidence with the expected original, high equivalency with the original values, and acceptable reproducibility, concluding that the SF-36 is reliable in evaluating healthy quality of life after it was linguistically adapted in
Colombian adults ${ }^{29}$

After evaluating self-perception with a single question, SRH was used to assess the perception individuals have of their own health in comparison to other people of the same age; this provides greater information than that offered by the concept of personal self-perception ${ }^{26}$. Table 1 shows the different questions that can be made when assessing state of health via SRH.

Also, when comparing the two questions with their possible responses to assess SRH, it has been found the WHO version discriminates the negative categories better, unlike the version from the United States that discriminates the positive categories better ${ }^{30}$. However, both types of questions are highly correlated and have shown similar associations with respect to demographic variables and health conditions, as well as having a similar variation pattern when applied in different countries $^{31}$.

\section{WHAT FACTORS DETERMINE SRH?}

Self-rated Health may be considered a global result of the measurement of multiple factors determining it. In fact, it is influenced by demographic variables like gender and age; social variables like social networks 
and family functioning; biological variables like the presence of illnesses and taking of medications; mental variables like suffering anxiety, depression, dementia, or grief; and, lastly, functional variables like presenting commitment in the physical and instrumental Daily Basic Activities ${ }^{8}$.

The different factors determining SRH by group of variables are:

Demographic variables. Regarding differences in SRH according to gender, diverse explanations have been considered among which there are differences in the state of health, wellbeing, and functionality and not in the greater or lesser possibility of one or the other sex reporting a determined state of health. This means the relationship between SRH and gender is mediated by other factors like educational level, illnesses, depression, and functional state. Here, it is worth mentioning that women report a greater proportion of health problems and have greater diagnosis of diseases like arterial hypertension, diabetes, musculoskeletal disorders, and accidents, aside from presenting greater frequency of affective disorders when compared to men. Given that women have higher life expectancies and, therefore, a greater possibility of enduring chronic disease that deteriorate their functionality, as those already mentioned, this could explain why they evidence greater association with the self-report of a bad $\mathrm{SRH}^{32}$.

Adding to the aforementioned, women have a higher life expectancy than men. This occurs at the expense of years lived with greater functional deterioration, that is, the consequences of the disease affect the internal and external perception of reality and translate to diminished quality of life when diminishing the possibilities of being and doing, which leads women to deteriorated perception of their own health and limitation of activities, functions, and opportunities ${ }^{11}$. Thus, better SRH has been constantly found in men than in women and this is more notorious in the elderly.

Another factor to bear in mind and that may explain a greater frequency of bad SRH in women is their lower income, which diminishes as they get older, and especially when they are very old ${ }^{10}$.

It has also been postulated that with the passage of time in the elderly, SRH tends to regular or poor, which can be explained by multiple factors, including the loss of social roles, chronic disease and disability among others $^{20}$. In spite of this, individuals over 90 years of age may paradoxically manifest good or excellent SRH, explained by different factors among which include:

- Heterogeneity of the aging process, which postulates that over the years - in spite of higher risk of illness and deterioration of the functional state, the elderly do not necessarily uniformly or inevitably manifest bad $\mathrm{SRH}^{18}$.

- Elderly adults take as reference groups other older individuals in whom disabilities are the norm, which leads them torate their health positively; additionally, over time they start establishing adaptive mechanisms to accept their own aging process, the presence of chronic disease, and functional limitations ${ }^{33}$.

- Elderly individuals are more optimistic regarding their health as they age, because they have become accustomed and perceive illnesses and functional impairment more optimistically than the younger individuals ${ }^{34}$.

- The survival effect, i.e., those reaching 85 years of age constitute the group with the highest optimism; while the most pessimist regarding their health may have already perished ${ }^{35}$.

- Elderly adults are a group that along the years has been exposed to multiple stressing events and subject to natural selection so survivors tend to be stronger and healthier ${ }^{34}$.

In addition, with the passage of years SRH may have multiple paths, which are determined by diverse biopsychosocial factors, consequently presenting great variability among individuals, which could also be related with the type of aging shown by the EA. The types of aging that have been described are successful, usual, or pathological ${ }^{36}$. EAs with successful aging, unlike those with usual or pathological aging, show high levels of physical, mental, and cognitive functioning, as well as lack of or low probability of developing disease or disability and an active commitment with life. EAs with usual aging present non-pathological losses related with age and in pathological aging there is evidence of disease with disability and its multiple bio-psychosocial consequences ${ }^{36}$.

Regarding the relationship between the type of aging and $\mathrm{SRH}$, it has been suggested that EAs with successful aging show good and stable SRH over time; however, SRH begins to deteriorate after 80 years of age. Nevertheless, paradoxically in some EAs 85 years of age and above SRH can stabilize or improve, which is 


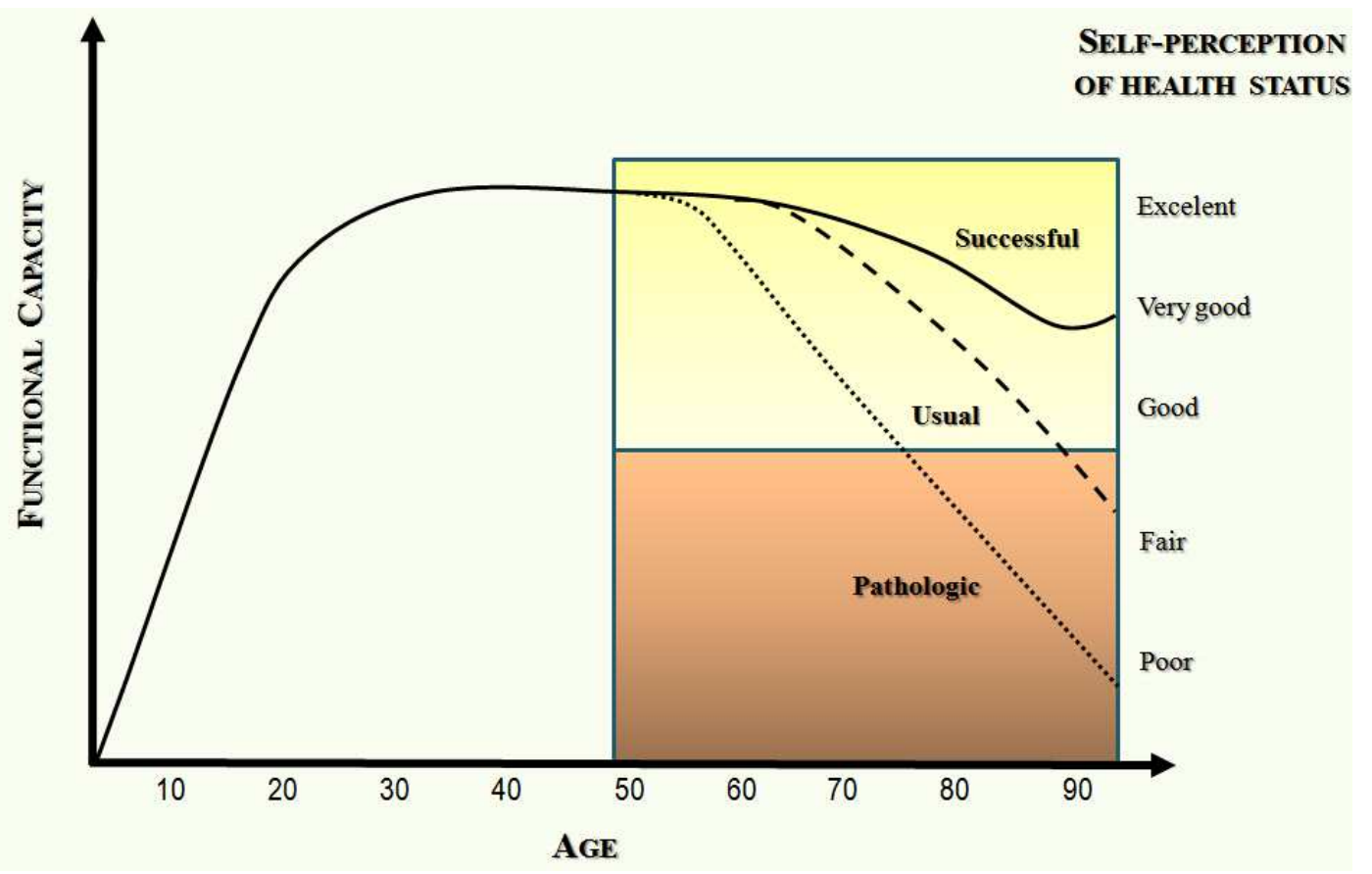

Graphic 3. Relationship among age, functional capacity, type of aging, and SRH Modified from: Rowe JW, Kahn RL. Successful aging. Gerontologist. 1997; 37: 433-40.

explained, as mentioned before, because it is an optimistic group and because it is the result of natural selection ${ }^{37}$. The elderly with usual aging report SRH similar to EAs with successful aging although the SRH impairment process begins earlier, around 70 years of age. Finally, EAs with pathological aging have bad SRH as a base and their impairment accelerates after 60 years of age $^{34}$. Graphic 3 displays the relationship among age, functional capacity, type of aging, and SRH.

A strong association has also been found between SRH and the population's socioeconomic level, given that the general state of health is better in individuals with higher socioeconomic levels ${ }^{11}$. However, exceptions are possible, particularly in certain populations of elderly adults, because this is a very heterogeneous group and this aspect may lead to important differences in the selfreport of health ${ }^{19,37}$.

Educational level is considered an important aspect determining better or worse SRH, inasmuch as individuals tend to have a better perception of their health when they have higher educational levels although they may have a greater number of illnesses ${ }^{26}$. It is considered that according to the educational level, the individual may have better tools to face vital stressing moments and, consequently, may modulate the result of $\mathrm{SRH}^{14}$.
Regarding geographical location factors influencing SRH assessment, it has been found that these differ from one country to another ${ }^{38}$. This diversity of patterns may be due to the demographic and epidemiological transition stage in which the populations are found ${ }^{39}$. For example, in healthier populations the perception of better health may depend to a greater extent on emotional health, on chronic disease, or on functionality problems; while in populations with the worse health, the general self-evaluation of health may be more affected by other health problems like infectious disease ${ }^{38}$. Another possible explanation for the differences found is that individuals with similar levels of health perceive their state of health differently in relationship with determined structural elements of the national sanitary systems like quality of healthcare services or the importance given to the illnesses they suffer ${ }^{19}$.

Likewise, the use of healthcare services may be associated with the evaluation of SRH; lowered use of sanitary services indicates better self-perception ${ }^{26}$. Results of longitudinal studies have revealed that survival is more related with subjective than with objective health and that healthcare is one of the factors associated with satisfactory aging ${ }^{35}$.

Although the subjectivity of SRH is acknowledged 
because it accounts for the perception people have of their own health, this may have advantages in cases where the population does not have generalized access to healthcare services ${ }^{37}$. Much of the information about the use of SRH in elderly adults and its relationship with other indicators comes from developed nations ${ }^{8}$. The assessment of the usefulness of this indicator in developing nations recently emerged with studies carried out in some countries in Latin America and Asia ${ }^{38}$.

In developed nations where there is greater contact between the population and sanitary personnel, it is possible that the self-report of specific disease like diabetes, arterial hypertension, or cancer is a better indicator of the population's health, because it is more objective than the general evaluation of one's own health ${ }^{40}$. However, even in developed nations, the selfreport of specific disease may enclose large bias ${ }^{41}$.

In general, it is suggested that during old age the decline of the ego is intensified, deriving into a loss of identity, low self-esteem, and decrease of social conducts $^{2}$. In spite of the aforementioned, having a stable relationship like a matrimony, participation in community activities, and joining social groups may help to maintain a sense of continuity including a more positive SRH, even after retirement ${ }^{37}$.

Biological variables. Prior awareness of an illness, particularly of chronic disease, suffered by the person, may affect the judgment the individual has of $\mathrm{SRH}^{42}$.

Self-Rated Health is specially influenced by somatic experience that generates the illness. Somatic experiences are physical manifestations that may be represented, for examples, by fatigue or a sensation of dyspnea, which can make individuals interpret they are suffering a serious condition and, consequently, modify their SRH. Knowledge of a potentially life threatening, serious disease like coronary disease or cancer, may have a greater impact on the individual, unlike knowing of a disease that impairs functionality but is not life threatening like osteoarthritis or hypertension, may lead to modifications of activities or behaviors and especially a change in SRH. Hence, SRH is considered the product of a process depending to a great extent on the information the individual has of the subjective experience generated by the disease ${ }^{43}$.

The presence of a disease may modify SRH, as can the clinical course; some diseases, especially those involving organic systems, like congestive heart failure, have periods of clinical stability but can also be intercalated with periods of exacerbation. Thus, SRH represents a complex judgment made by the individual at a given moment on the severity of the current state of health, because the course of a disease can be modified over time.

Also, in spite these being personal perceptions EAs of their own health, some studies have shown that the morbidity they perceive coincides by two thirds with that diagnosed by health professionals ${ }^{32}$. In studies, it has often been found an excellent or very good SRH in individuals with good physical health; however, paradoxically, it has also been noted that individuals with these same physical health characteristics have regular or poor SRH. Later analyses have shown that these individuals have symptoms of depression or dissatisfaction with their lives ${ }^{18}$.

Mental variables. One of the reasons why the selfconcept, SRH, and their relationship with age suppose a problem is the perception by EAs of feeling psychologically worse ${ }^{34}$. Indeed, depression is one of the most frequent mental disorders for EAs. Prevalence for major depression has been described at $1 \%-5 \%$ and a frequency of $8 \%-27 \%$ for significant symptoms of depression in EAs living in the community ${ }^{44}$. The prevalence is greater in hospitalized elderly subjects, and in those living nursing homes ${ }^{45}$. Frequently, depression emergesinEAsin atypical manner and does not fulfill the clinical criteria for major depression. These incomplete syndromes are denominated minor depression or subsyndromal depression according to the diagnostic statistical manual for mental disorders (DSM-IV) and have the same repercussions, in terms of morbidity and mortality, as major depression ${ }^{46}$.

Depression may involvecognitive processing, causing individuals to manifest lower satisfaction with their lives and, consequently, worse SRH. Studies have shown that EAs with depression or dementia reveal worse SRH compared to those who do not present any of these disorders 9 .

Theevaluation of SRHinEAs withdepression, dementia, or delirium may be complex. Cognitive impairment, per se, acts as an independent predictor for mortality ${ }^{47}$.

Regarding the relationship between the cognitive state and SRH, some authors consider that cognitive alteration may make the SRH report unreliable, particularly in patients with dementia ${ }^{48}$.

Others, on the contrary, consider that SRH is not altered. Walker et $a l .{ }^{49}$ conducted a prospective 
population study with 8,697 elderly adults living in the community in ten Canadian provinces to evaluate if SRH behaved as an independent predictor for survival and determine if the cognitive function could modify such relationship. It was found that SRH was a valid measurement and predictive of survival in elderly adults with minimal, slight, and moderate cognitive impairment. This shows the complexity of the cognitive process in said relationship and given that $\mathrm{SRH}$ is a subjective measurement it may reflect the state of health the same way other objective measurements do, like the presence of co-morbidity or the assessment of the functional state, within a broad range of cognitive functioning.

Functional variables. It is suggested that many chronic diseases have direct effects on SRH, independently of the presence of disability or functional limitation. Lammi et $a l .{ }^{50}$ concluded that in contrast to the Framingham study, diseases by themselves are stronger predictors of disabilities than unhealthy habits, and that EAs judge their quality of life and their health, more from the point of view of the capacity to independently perform or not their daily life activities.

Likewise, there is awareness of the association between co-morbidity and functional impairment in physical and instrumental Basic Daily Activities. Indeed, and as was already mentioned throughout this text, the functional state is an important factor in determining $\mathrm{SRH}$, which shows the complexity of the multiple interactions existing between the different factors determining it ${ }^{51}$.

From another vantage point, although functional impairment and the presence of chronic disease are important factors for the formation of the subjective concept of a bad SRH; in spite of this, EAs with chronic disease may report a good SRH. Such is the case of the Ontario health survey conducted in 1990, where it was found that $79 \%$ of those with chronic disease and $50 \%$ of those with long-term disability reported good or excellent $\mathrm{SRH}^{52}$. This suggests that in spite of the presence of chronic disease or disability, many EAs can perceive their state of health favorably.

\section{WHAT ADVERSE HEALTH EVENTS CAN SRH PREDICT?}

Self-Rated Health has been associated with health events like disease, death, hospitalization, and functional impairment among others; however, some of the factors determining SRH have also been associated independently to health events, which lead to inferring that SRH acts as an intermediate variable.

The capacity of SRH to foresee morbidity has been considered good. Some studies have shown that perceived morbidity coincides by two thirds with morbidity diagnosed by healthcare personnel ${ }^{32}$. The variables with greater association with the self-report of poor SRH are the presence of chronic disease like hypertension, diabetes, urinary tract disease, renal failure, acute illness, and functional like being disabled, suffering a mental or physical disability or limitation ${ }^{53}$. Hence, the perception of health and the factors associated with such may be used to assess the level of health of the population of elderly adults and its determinants ${ }^{53}$.

Also, during the last 20 years there has been an important increase in studying SRH as a predictor of mortality. Most studies find a significant association between SRH and mortality ${ }^{54}$. Others have found that the predictive value decreases, even losing its significance when the analysis is adjusted according to other factors, like prior morbidity or functional capacity ${ }^{55}$. Differences in adjustment variables are also mentioned in the perception due to gender or idiosyncratic variations in the population studied ${ }^{16}$.

Among the arguments postulated to explain the capacity of SRH to predict mortality, we have found, in the first place, past and current knowledge of the health experience implying that EAs make a comparison of their own health with people of similar age and state of health, and in the second place, the personal health practices influencing on the health results ${ }^{56}$.

The relationship among SRH, mortality, and gender, is controversial. In some studies, a stronger association has been demonstrated in males than in females and a loss of meaning has been observed in women when adding other variables, like the objective state of health when participating in the interview ${ }^{57}$. In contrast, other studies have found the opposite effect, with a stronger association in women ${ }^{58}$. These differences among different studies may be explained by the fact that SRH does not have a unique point of reference; individuals use personal perceptions, information from their neighbors and friends, as well as objective medical information to have an idea of their state of health.

Also, regarding the relationship among socio- 
demographic factors, $\mathrm{SRH}$, and mortality, it is considered that said information may differ according to gender, the moment of the vital cycle, or the social context. For these reasons, it is interesting to study the relationship between SRH and mortality in different populations and with different social contexts ${ }^{59}$. The results among these three aspects, socio-demographic factors, SRH, and mortality, have been contradictory because some researchers have found that poor SRH is associated to increased risk of death, even after adjusting it according to a broad spectrum of socio-demographic variables acting as potential confounders ${ }^{16}$. Other studies have not found a clear relationship between SRH and mortality after adjusting it according to demographic, socioeconomic, and clinical variables or psychosocial factors ${ }^{9}$. Some authors have suggested possible explanations for these contradictions, which include differences in the methods and ways of making the questions and different types of response forms. There is also reference to differences in the variables used for adjustment, differences in perception due to gender or variations in the idiosyncrasy of the population studied ${ }^{16}$.

It is worth pointing out that studies in which the relationship between SRH and mortality has been researched, the question has been dichotomized in the following manner: good with options good and excellent and poor, which includes regular, poor, and very poor. Furthermore, by including multivariate logistic regression models, it was possible to evaluate the association between SRH and mortality by adjusting for different variables like chronic disease, habits (smoking, alcohol), functionality, socioeconomic level, and others. When introducing these analysis models, from decreased relative risk to a slight increase in the association have been found. For example, a study carried out with elderly Finish men during a 6-year period revealed a decrease in the association of relative risk between mortality and poor SRH, which decreased from 3.76 to 2.12 when the analysis was adjusted for eight risk factors (body mass index, smoking, HDL cholesterol, LDL cholesterol, blood pressure, physical activity, alcohol consumption, and income $)^{60}$. When a further analysis was done for eight chronic diseases, the association diminished to 1.69. There is a quantitative-type interaction because the means of association of the effect have the same direction. Additionally, although the last relative risk is lower, it is statistically significant and represents a $69 \%$ increase in mortality for individuals reporting poor SRH.

Regarding the relationship among measurements of SRH repeated over time and its capacity to predict adverse health events, mixed results may be found. Leinonen et al. ${ }^{61}$ conducted a cohort study with elderly Finish subjects and after a follow up of the subjective assessment of the state of health, they stated that stability is more common than change in this assessment and systematically reflects the health conditions, the functional capacity, as well as physical and social activities. For the authors, the high stability in selfperception indicates that with increased age, the elderly subjects adapt to worse health conditions. This adaptation plays an important role that is reflected in the subjective evaluation. Thus, the evident deterioration in the objective evaluations is not subjectively reflected and the authors suggest that the adaptation strategies to this deterioration are given by modifications of expectations, aspirations, and standards or that they see it as part of the normal aging process and adjust their standards of good health accordingly. Furthermore, age-related impairment is usually a gradual process to which they adapt slowly, without simultaneously modifying their SRH; that is, there is a cognitive reorganization for new internal processes. The stability may also indicate comparison with other individuals in worse conditions or with greater disadvantages. The few fluctuations in self-perception are given by big or abrupt changes in the state of health or in the symptomatology of the diseases, which also cause changes in the functional capacity ${ }^{61}$. Given that SRH depends upon multiple factors and among these there are the socioeconomic variables, said hypotheses should be proven in developing nations so they can be accepted and in this sense avail of their usefulness in our environment ${ }^{38}$.

In terms of the cognitive function and the relationship between SRH and mortality, it is known that SRH may adequately predict mortality in EAs with slight, minimal and moderate cognitive impairment. For severe impairment, its capacity to predict is affected and factors like age and functional impairment take on greater importance ${ }^{49}$.

Likewise, SRH has been associated as a predictive variable for hospitalization, development of falls, functional impairment in the physical and instrumental Daily Basic Activities, a greater demand for healthcare 
services and institutionalization in nursing homes, after being adjusted for possible confounding factors like socio-demographic variables ${ }^{16}$.

In conclusion, the concept of SRH has been broadly used, given that it is a reliable and easily obtained measurement of the general state of health, because it permits integrating a subjective measurement as an indicator. Self-Rated Health is determined by the physical function, the presence of disease, the existence of disabilities and functional limitations. It has been associated with adverse health events like mortality, use of healthcare services and impairment of physical and instrumental Daily Basic Activities, becoming an important variable to assess the state of health in the elderly.

\section{REFERENCES}

1. Manton KG,GuX, Lamb VL. Change in chronic disability from 1982 to 2004/2005 as measured by long-term changes in function and health in the U.S. elderly population. Proc Natl Acad Sci. 2006; 103: 18374-79.

2. Ocampo JM, Londoño I. Ciclo vital individual: vejez. Rev Asoc Colomb Gerontol Geriatr. 2007; 21: 1072-84.

3. WHO. Constitución de la Organización Mundial de la HealthGeneva, 1945. Date available: 6 November 2009.

4. Ocampo JM. Estrés y enfermedades del adulto mayor. En: Herrera JA (ed). Psiconeuroinmunología para la práctica clínica. Cali: Programa Editorial Universidad del Valle; 2009. p. $109-28$.

5. Ocampo JM. Evaluación geriátrica multidimensional del anciano en cuidados paliativos. $P \& B$ 2005; 9: 45-58.

6. Meléndez JC. La autopercepción negativa y su desarrollo con la edad. Geriatrika. 1996; 12: 389-1996.

7. Griffiths P, Ullman R, Harris R. Self-assessment of health and social care needs by older people: a multi-method systematic review of practices, accuracy, effectiveness and experience. London: NCCSDO, 2005. Date available: 18 December 2006. Available in: http://www.sdo.lshtm.ac.uk/sdo302002.html

8. Bjorner, JB, Kristensen TS, Orth-Gomér K, Tibblin G, Sullivan M, Westerholm P. 1996. Self-rated health: A useful concept in research, prevention and clinicalmedicine. Stockholm: Swedish Council for Planning and Coordination of Research.

9. Idler EL, Benyamini Y. Self-rated health and mortality: a review of twenty-seven community studies. J Health Soc Behav. 1997; 38: 21-37.

10. Aspiazu GM, Cruz JA, Villagrasa FJR, Abanades HJC, García MN, Valero FA. Factores asociados a mal state of health percibido o mala calidad de vida en personas mayores de 65 años. Rev Esp Health Publica. 2002; 76: 683-99.

11. Damian J, Ruigomez A, Pastor V, Martín-Moreno JM. Determinants of self assessed health among Spanish older people living at home. J Epidemiol Community Health. 1999; 53: 412-6.
12. World Health Organization. Statistics Netherlands. Health interview surveys: towards international harmonization of methods and instruments. Vol. 58. Copenhagen: WHO Regional Office for Europe, WHO Regional Publications, European; 1996.

13. Engel G. The need for a new medical model: a Challenge for biomedicine. Science. 1977; 196: 129-36.

14. Borrell-Carrio F, Suchman AL, Epstein R. The bio-psychosocial model 25 years later: principles, practice and scientific inquiry. Ann Fam Med. 2004; 2: 576-82.

15. Von Bertalanffy LV. Teoría general de los sistemas. México: Fondo de Cultura Económica; 1998.

16. Lee Y. The predictive value of self assessed general, physical, and mental health on functional decline and mortality in older adults. J Epidemiol Community Health. 2000; 54: 123-9.

17. Ubel PA. What should I do, doc?: Some psychological benefits of physician recommendations. Arch Intern Med. 2002; 162: 977-80.

18. Blazer DG. How do you feel about...? Health outcomes in late life and self-perceptions of health and well-being. Gerontologist. 2008; 48: 415-22.

19. Wong R, Peláez M, Palloni A. Autoinforme de health general en adultos mayores de América Latina y el Caribe: su utilidad como indicador. Rev Panam Health Publica. 2005: 17: 32332.28 .

20. Gómez JF, Curcio CL, Matijasevic F. Autopercepción de health, presencia de enfermedades y discapacidades en ancianos de Manizales. Rev Asoc Colomb Gerontol Geriatr. 2004; 18: 706-15.

21. Parra DC, Gómez LF, Sarmiento OL, Buchner D, Brownson R, Schimd T, et al., Perceived and objective neighborhood environment attributes and health related quality of life among the elderly in Bogotá, Colombia. Soc Sci Med. 2010; 70: 10706.

22. Hambleton IR, Clarke K, Broome HL, Fraser HS, Brathwaite F, Hennis AJ. Historical and current predictors of self-reported health status among elderly persons in Barbados. Rev Panam Health Publica. 2005; 17: 342-52.

23. Alves LC, Rodrígues RN. Determinants of self-rated health among elderly persons in São Paulo, Brazil. Rev Panam Health Pública. 2005; 17: 333-41.

24. Reyes-Ortiz CA, Peláez M, Koenig HG, Mulligan T. Religiosity and self-rated health among Latin American and Caribbean elders. Int J Psychiatry Med. 2007; 37: 425-43.

25. Department of Health. 2002. Guidance on the single assessment process for olderpeople. HSC 2002/001; LAC (2002)1. London: Department of Health.

26. Bjorner JB, Tage SK, Orth-Gomér K, Gösta T, Sullivan M, Westerholm P. Self-rated health: a useful concept in research, prevention, and clinical medicine. Stockholm: Ord \& Form AB; 1996.33

27. Ware JEJr, Sherbourne CD. The MOS 36-item short-form health survey (SF-36) (I). Conceptual framework and item selection. Med Care. 1992; 30: 473-83.

28. McHorney CA, Ware JEJr, Raczek AE. The MOS 36-Item short-form health survey (SF-36): II. Psy-chometric and clinical tests of validity in measuring physical and mental health 
constructs. Med Care. 1993; 31: 247-63.

29. Lugo LH, García HI, Gómez C. Confiabilidad del cuestionario de calidad de vida en health SF-36 en Medellín, Colombia. Rev Fac Nac Health Publica. 2006; 24: 37-50.

30. Eriksson I, Unden AL, Elofsson S. Self-rated health. Comparisons between three different measures. Results from a population study. Int J Epidemiol. 2001; 30: 326-33.

31. Jürges H, Avendano M, Mackenbach JP. Are different measures of self-rated health comparable? An assessment in five European countries. Eur J Epidemiol. 2008; 23: 773-81.

32. Seculi E, Fuste J, Brugulat P, Junca S, Rue M, Guillen M. Percepción del state of health en varones y mujeres en las últimas etapas de la vida. Gac Sanit. 2001; 15: 217-23.

33. Hoeymans N, Feskens EJM, Van den Bos GAM, Kromhout D. Measuring functional status: cross sectional and longitudinal association between performance and self-report (Zutphen Elderly Study 1990-1993). Clin Epidemiol. 1996; 49: 1103-10.

34. Liang J, Shaw BA, Krause N, Bennett JM, Kobayashi E, Fukaya T, et al. How does self-assessed health change with age? A study of older adults in Japan. J Gerontol B Psychol Sci Soc Sci. 2005; 60: S224-32.

35. Idler EL. Age differences in self-assessments of health: age changes, cohort differences, or survivorship? J Gerontol Soc Sci. 1993; 548: S289-300.

36. Fries JF. Successful aging. An emerging paradigm of gerontology. Clin Geriatr Med. 2002; 18: 371-82.

37. Wong R. La relación entre health y nivel sociodemográfico entre adultos mayores: diferencias por género. En: Salgado de Snyder V, Wong R, eds. Envejeciendo en la pobreza: género, health y calidad de vida. México, DF: Instituto Nacional de Health Pública; 2004. p. 97-122.

38. Palloni A, Pinto-Aguirre G, Peláez M. Demographic and health conditions of ageing in Latin America and the Caribbean. Int J Epidemiol. 2002; 31: 762-71.

39. Albala C, Lebrão ML, León Díaz EM, Ham-Chande R, Hennis AJ, Palloni A, et al. Encuesta Health, Bienestar y Envejecimiento (SABE): metodología de la encuesta y perfil de la población estudiada. Rev Panam Health Pública. 2005; 17: 307-22.

40. Wallace R, Herzog AR. Overview of the health measures in the Health and Retirement Study. J Hum Resour. 1995; 30: S84107.

41. Baker M, Stabile M, Deri C. What do self-reported, objective, measures of health measure? J Hum Resour. 2004; 39: 106793.

42. Menéndez J, Guevara A, Arcia N, León-Díaz EM, Marín C, Alfonso JC. Enfermedades crónicas y limitación funcional en adultos mayores: estudio comparativo en siete ciudades de América Latina y el Caribe. Rev Panam Health Pública. 2005; 17: 353-61.

43. Leventhal H, Diefenbach M, Leventhal EA. Illness cognition: using common sense to understand treatment adherence and affect cognition interactions. Cogn Ther Res. 1992; 16: 143-63.

44. Ocampo JM, Romero N, Saa HA, Herrera JA, Reyes-Ortiz CA. Prevalencia de las prácticas religiosas, disfunción familiar, soporte social y síntomas depresivos en adultos mayores. Cali, Colombia 2001. Colomb Med. 2006; 37 (Supl 1): 26-30.66.
45. Blazer DG. Depression in late life: review and commentary. $J$ Gerontol A Biol Sci Med Sci. 2003; 58: 249-65.

46. Lavretsky H, Kumar A. Clinically significant non-major depression: old concepts, new insights. Am J Geriatr Psychiatry 2002; 10(3):239-55.

47. Anstey KJ, Luszcz MA, Giles LC, Andrews GR. Demographic, health, cognitive, and sensory variables as predictors of mortality in very old adults. Psychol Aging. 2001; 16: 3-11.

48. Hickey EM, Bourgeois MS. Health-Related Quality of Life (HRQOL) in nursing home residents with dementia: Stability and relationship among measures. Aphasiology. 2000; 14: 66979.

49. Walker JD, Maxwell CJ, Hogan DB, Ebly EM. Does self-rated health predict survival in older persons with cognitive impairment? J Am Geriatr Soc. 2004; 52: 1895-900.

50. Lammi UK, Kivela SL, Nissinen A. Predictors of disability in elderly Finish men. A longitudinal study. J Clin Epidemiol. 1989; 42: 1215-25.

51. Idler EL, Kasl SV. Self-ratings of health: do they also predict change in functional ability? J Gerontol Soc Sci. 1995; 50B: S344-53.

52. Badley EM, Yoshida K, Webster G. Disablement and chronic health problems in Ontario. Ontario Health Survey 1990. Working Paper $N^{\circ}$ 5. Toronto: Ministry of Health; 1993.

53. Lima-Costa MF, Firmo JO, Uchoa E. The structure of selfrated health among older adults: the Bambui health and ageing study (BHAS). Rev Saude Publica. 2004; 38: 827-34.

54. Heistaro S, Jousilahti P, Lahelma E, Vartiainen E, Puska P. Self rated health and mortality: a long term prospective study in eastern Finland. J Epidemiol Community Health. 2001; 55: 227-32.

55. Murata C, Kondo T, Tamakoshi K, Yatsuya H, Toyoshima H. Determinants of self-rated health: Could health status explain the association between self-rated health and mortality? Arch Gerontol Geriatr. 2006; 43: 369-80.

56. Benyamini Y,LevanthalEA, Levanthal H. Self-assessments of health: What do people know that predicts their mortality? Res Aging. 1999; 21: 477-500.

57. Idler EL, Russell LB, Davis D. Survival, functional limitations, and self-rated health in the NHANES I epidemiologic followup study, 1992. Am J Epidemiol. 2000; 152: 874-83.

58. Leinonen R, Heikkinen E, Jylhä M. Predictors of decline in selfassessments of health among older people: a 5-year longitudinal study. Soc Sci Med. 2001; 52: 1329-41.

59. Heistaro S, Laatikainen T, Vartiainen E, Puska P, Uutela A, Pokusajeva S, et al., Self-reported health in the Republic of North Karelia, Russia and in North Karelia, Finland in 1992. Eur J Public Health. 2001; 11: 74-80.

60. Kaplan GA, Goldberg DE, Everson SA, Cohen RD, Salonen R, Tuomilehto J, et al. Perceived health status and morbidity and mortality: evidence from the Kuopio ischaemic heart disease risk factor study. Int J Epidemiol. 1996; 25: 259-65.

61. Leinonen R, Heikkinen E, Jylha M. Changes in health, functional performance and activity predict changes in self-rated health: a 10-year follow-up study in older people. Arch Gerontol Geriatr. 2002; 35: 79-92. 